\title{
Enfermedades infecciosas pediátricas: el crup en La fuerza del cariño (1983)
}

DOI: https://dx.doi.org/10.14201/rmc.20236

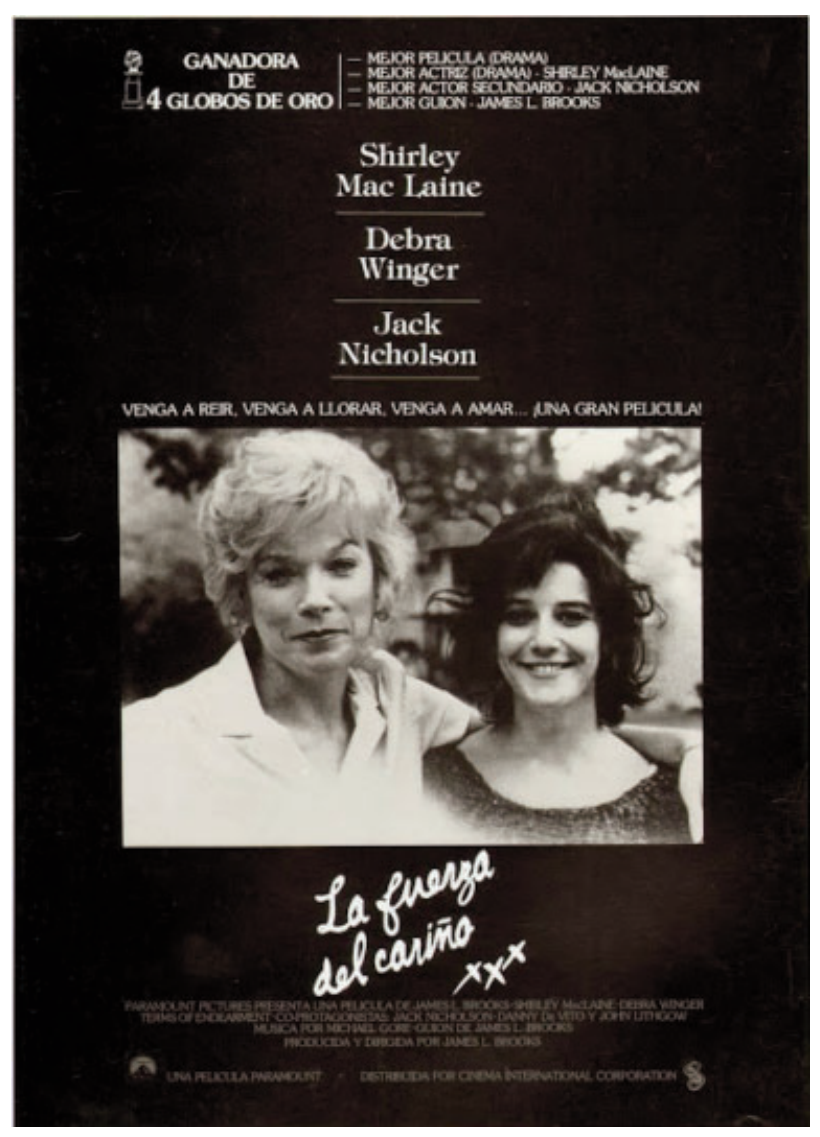

Cartel en español.

Acción: Houston (Tejas), Des Moines (lowa), Nebraska y Nueva York (La historia trascurre durante 30 años).

\section{Ficha técnica}

Título original: Terms of Endearment. País: Estados Unidos.

Año: 1983.

Director: James L. Brooks.

Música: Michael Gore.

Fotografía: P. Andrzej Bartkowiak.

Montaje: Richard Marks.

Guion: James L. Brooks sobre la novela homónima de Larry McMurtry.

Intérpretes: Shirley MacLaine, Debra Winger, Jack Nicholson, Danny DeVito, Jeff Daniels, John Lithgow, Lisa Hart Carroll, Betty King, Huckleberry Fox, Troy Bishop, Shane Serwin, Megan Morris, Tara Yeakey, Norman Bennett, Jennifer Josey,...

Color: color.

Duración: 132 minutos.

Género: comedia, drama.

Idioma original: inglés.

Productoras: Paramount Pictures.

Sinopsis: "Aurora (Shirley MacLaine) y Emma (Debra Winger) son una madre y una hija muy unidas, pero con puntos de vista muy distintos sobre la vida. Aurora, que está viuda, es una mujer temperamental, pero de buen corazón, y Emma es una joven rebelde que está deseando salir de casa e independizarse; lo malo es que para conseguirlo sigue el camino más convencional: casarse. Por su parte, Aurora tiene un romance otoñal con un exastronauta (Jack Nicholson). A través de los años, madre e hija intentan siempre buscar la forma de soportarse y encontrar la felicidad." (FilmAffinity).

Premios: Premios: Oscar a la Mejor Película, Director, Actriz Principal (Shirley MacLaine), Actor Secundario (Jack Nicholson) y Guion Adaptado.

Disponibilidad: La fuerza del cariño (DVD). Madrid: Paramount Pictures; 2001.

Comentario explicativo: Debra tiene dos hijos y una hija. La niña sufre un crup. En la versión doblada en castellano en España "croup" se traduce por difteria. Esta enfermedad produce dificultad respiratoria, pero tiene un nombre especifico en inglés.

\section{Enlaces:}

https://www.filmaffinity.com/es/film560543.html https://www.filmaffinity.com/en/film560543.html https://www.imdb.com/title/tt0086425

Trailer en inglés 


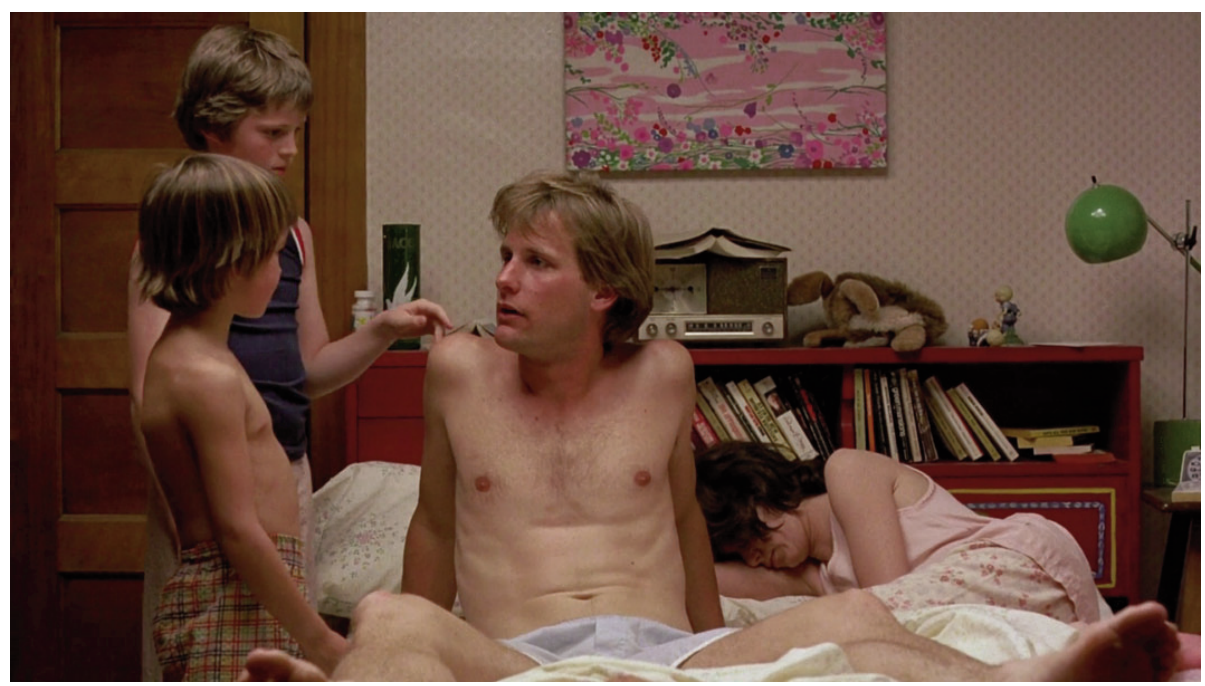

Presentación nocturna ("Despierta papa, Melanie esta mala").

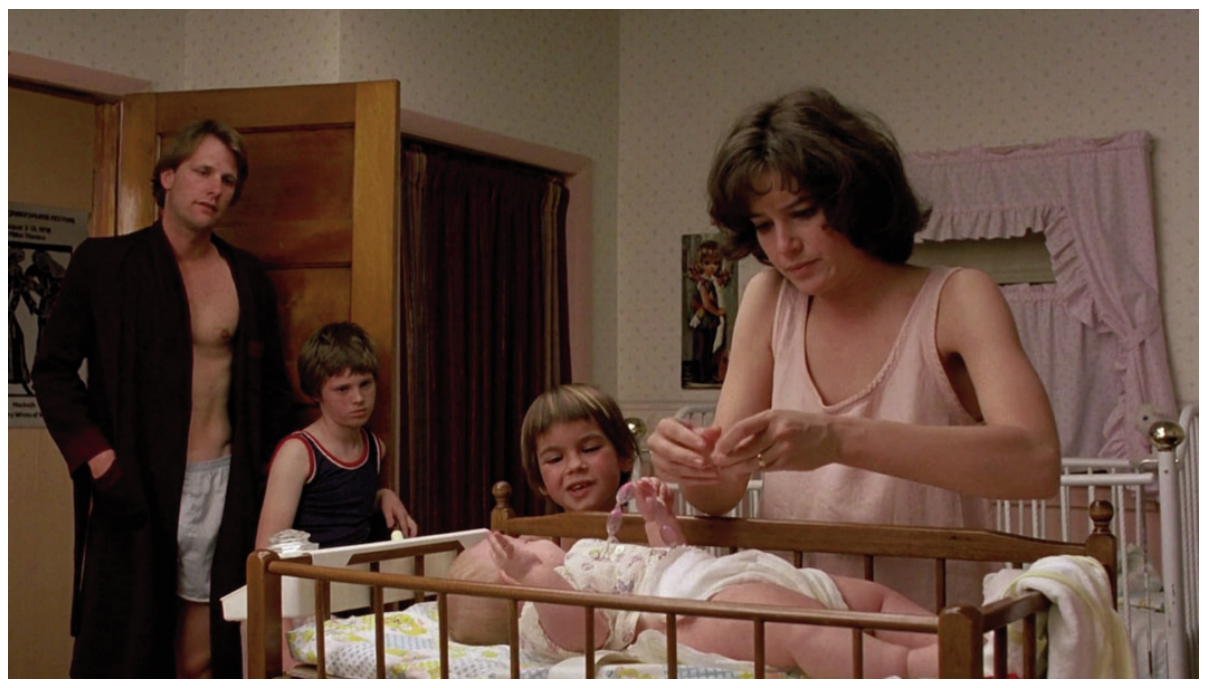

Afecta a los niños. 


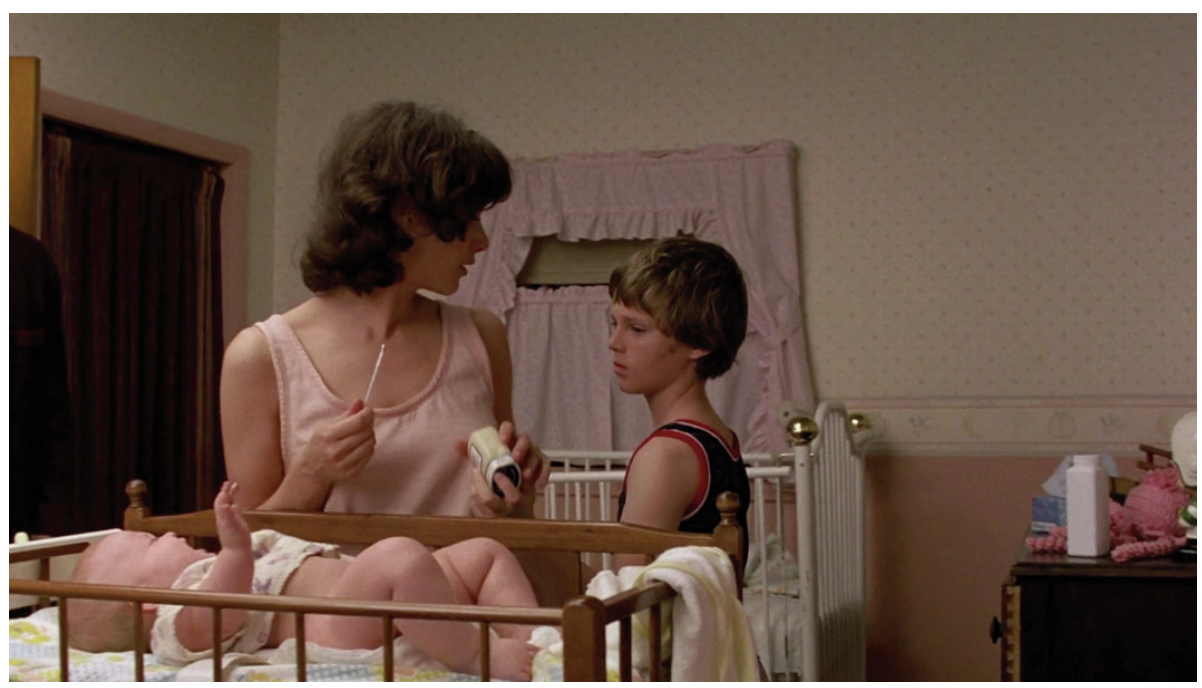

Presenta entre otras manifestaciones fiebre (en la película no se dice que la tenga, solo se toma la temperatura).

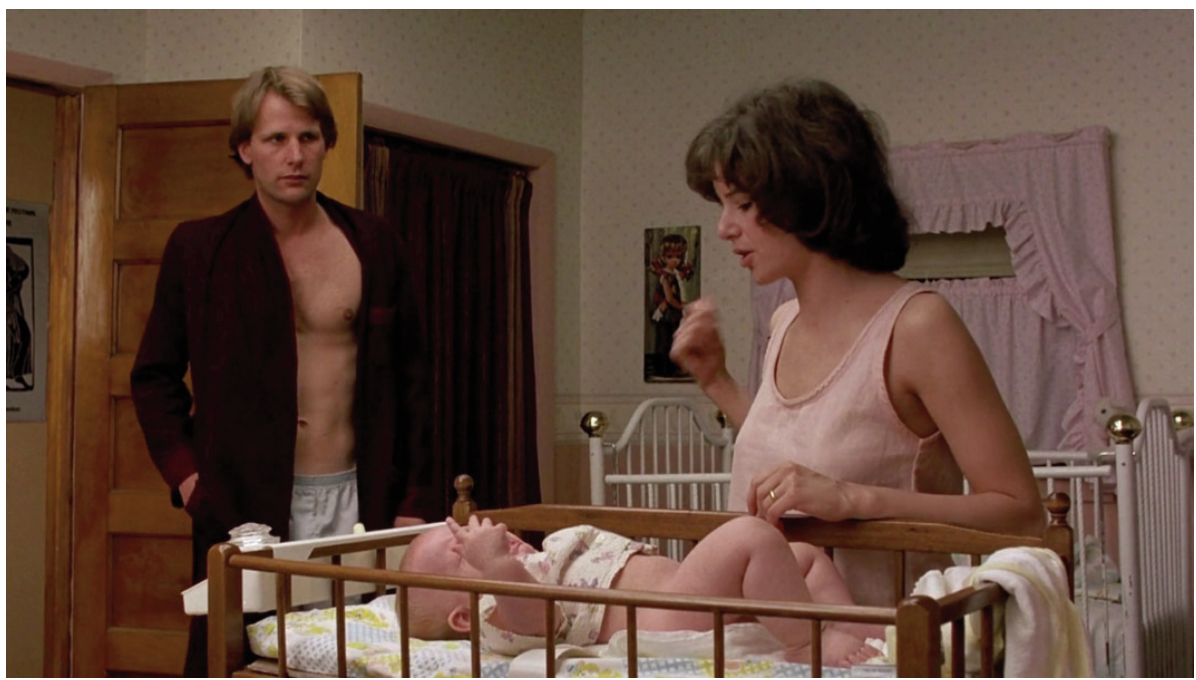

"Seguro que es el crup ¿Recuerdas, Tommy lo tuvo dos veces?” (En la versión española: “¿Te acuerdas cuando la tuvo Tommy?"). 


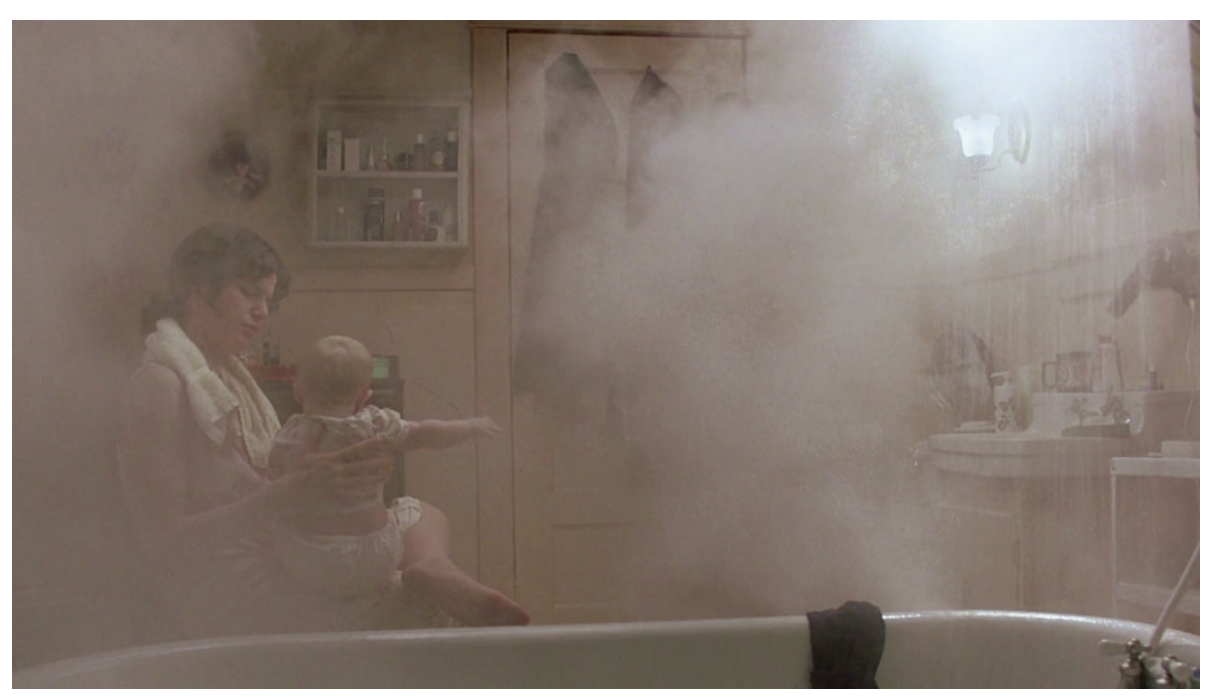

"Dios mío que tos más fea" (perruna).

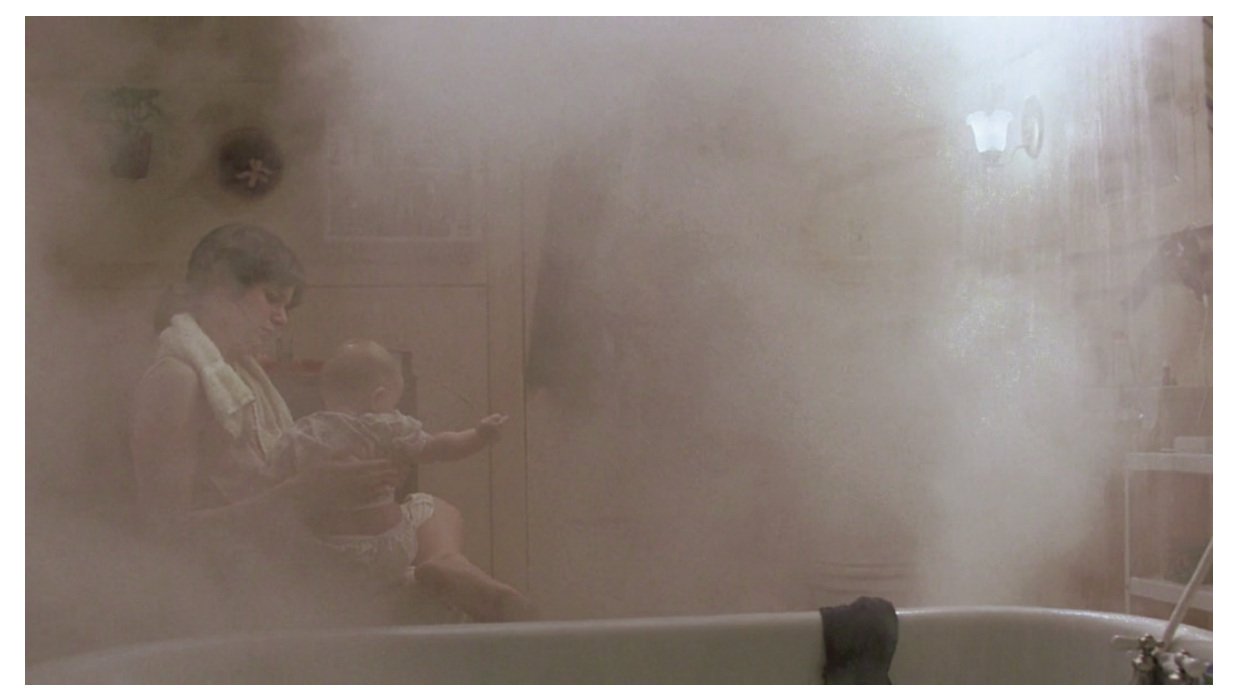

Las formas leves generalmente se tratan en el domicilio. El ambiente húmedo cálido generado por una ducha parece ser beneficioso. 


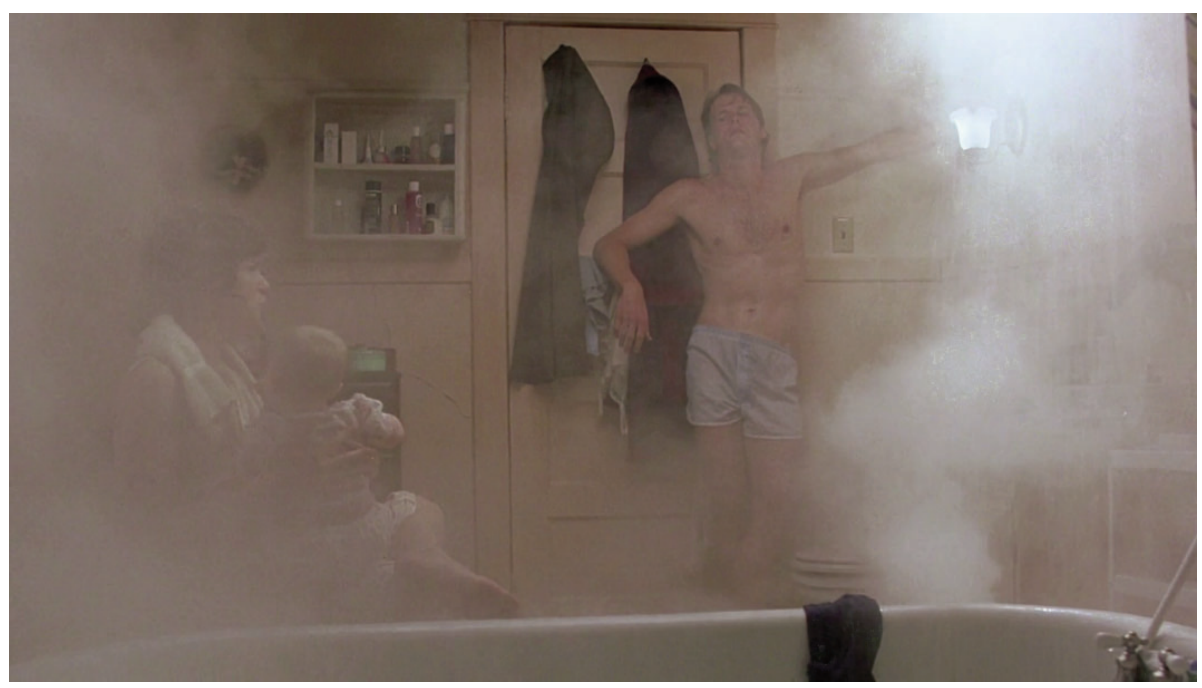

"Cuanto tiempo la vas a tener aqui".

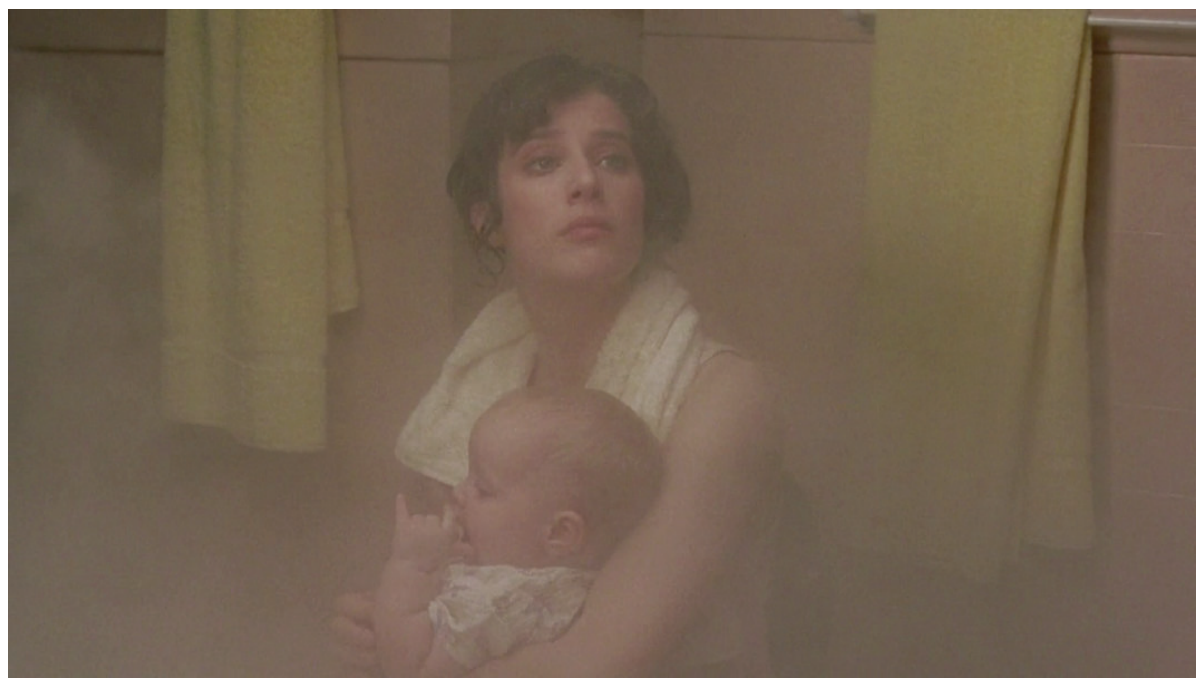

"No lo sé, hasta que se le aclare la garganta o yo pierda 10 kilos, ..., unos 20 minutos, supongo". 


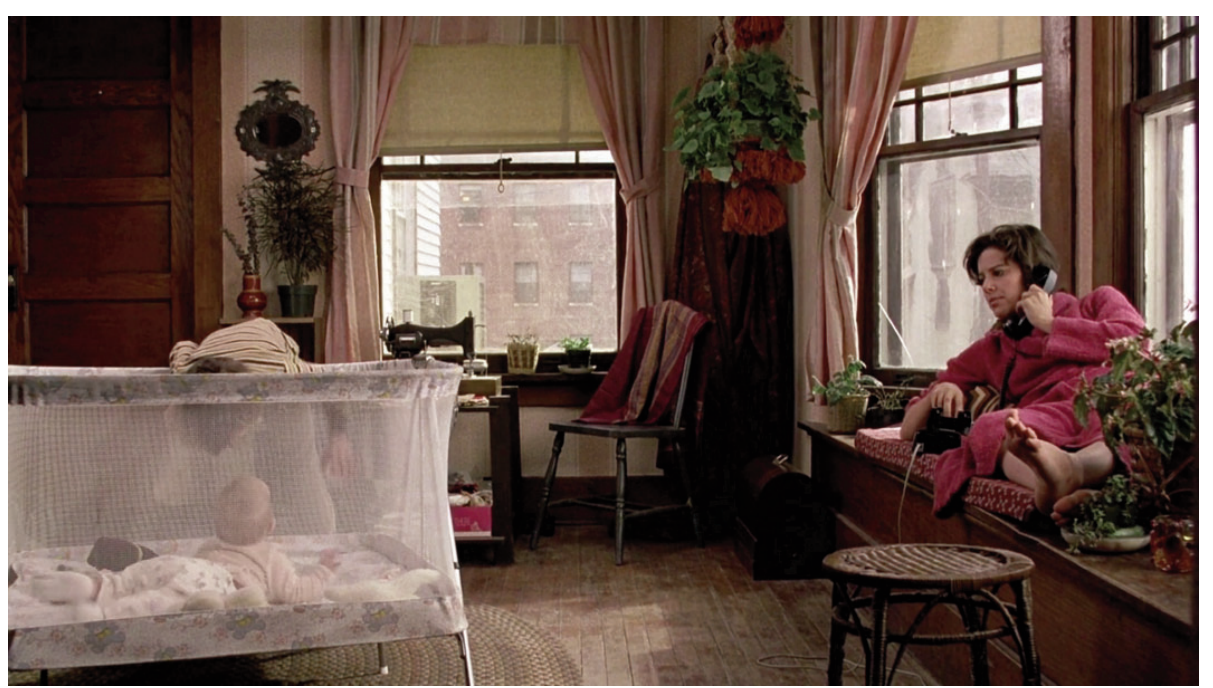

El crup es una infección respiratoria vírica (generalmente) aguda de corta duración (Al día siguiente: “No beses a la niña, aun puede estar enferma").

María GARCÍA MORO¹, Enrique GARCÍA SÁNCHEZ2,3,4, José Elías GARCÍA SÁNCHEZ2,3,4

$1_{\text {Facultad de Farmacia. Universidad de Salamanca (España). }}$

2 Departamento de Ciencias Biomédicas y del Diagnóstico. Facultad de Medicina. Universidad de Salamanca (España).

3IUCE (Instituto Universitario de Ciencias de la Educación). Universidad de Salamanca (España).

${ }^{4}$ IBSAL (Instituto de Investigación Biomédica de Salamanca) (España).

Autor para correspondencia: José Elias García Sánchez. Correo electrónico: joegas@usal.es

Como citar este artículo: García Moro M, García Sánchez E, García Sánchez JE. Enfermedades infecciosas pediátricas: el crup en La fuerza del cariño (1983). Rev Med Cine [Internet] 2019;15(1): 49-54.

DOI: https://dx.doi.org/10.14201/rmc.20236 